\title{
Revaloración del Mundo Primigenio en la Poesía de SOLEDAD FARIÑA*
}

\section{Olga Grandón Lagunas**}

\section{Resumen}

La presencia de una madre mítica asociada a espacios nortinos y poseedora de una lengua en gestación y originaria es tema muy significativo en los siguientes libros de Soledad Fariña (Antofagasta, Chile, 1943): El Primer Libro (1985), Albricia (1988), En Amarillo Oscuro (1994) y Pac Pac Pec Pec (2012). Nuestro trabajo se enmarca dentro del objetivo final de una investigación a largo plazo, la que se aboca a entender los diversos procesos imaginarios, situados en los contextos culturales y sociales, en búsqueda de identidades. Esos contextos son, finalmente, los que contribuyen no solo a la gestación imaginaria de visiones y textos, sino al sentido que finalmente les atribuimos, en tanto objetos pertenecientes a un territorio relacionado con la cultura andina en general, y con Perú y el Norte Grande de Chile en específico.

Palabras clave: Poesía chilena, cultura andina, subjetividad femenina.

\section{Reconsidering the Primary World in Soledad FARIÑA'S POETRY}

\begin{abstract}
The mythical mother's presence associated with northern spaces, holder of a native and in gestation language, is a significant topic in Soledad Farina's following books (Antofagasta, Chile, 1943): El Primer Libro (1985), Albricia (1988), En Amarillo Oscuro (1994) y Pac Pac $\mathrm{Pec} P e c$ (2012). Our application is in line with a long term research whose final objective is the understanding of the various imaginary process in search of identities, in social and cultural contexts. Eventually, these contexts contribute not only to the imaginary gestation of visions and texts, but also to the sense that we give them as objects belonging to a cultural territory related to the Andean Culture in general and to Peru and the North of Chile (Norte Grande) specifically.
\end{abstract}

Keywords: Chilean poetry, andean culture, feminine subjectivity.

Recibido: 10-03-2015

Aceptado: 23-01-2016

* $\quad$ Este estudio es resultado del Proyecto FONDECYT regular 2012, N 1120614: “Cartografía literaria del Norte Grande", cuyo Investigador Principal es el Profesor Mauricio Ostria de la Universidad de Concepción, en el que participo como coinvestigadora. Fue también presentado como ponencia en el XVIII Congreso Internacional de la Sociedad Chilena de Estudios Literarios en noviembre de 2012.

** Chilena. Doctora en Literatura, Universidad de Chile. Académica Universidad de Antofagasta, Antofagasta, Chile. olga.grandon@uantof.cl 


\section{Introducción}

Aunque la presencia de una madre mítica asociada a espacios nortinos andinos y poseedora de una lengua en gestación y originaria no es nueva en los imaginarios construidos por la lírica chilena contemporánea especialmente de poetas mujeres como Gabriela Mistral ${ }^{1}$ - el tema cobra especial relevancia y sentido en la obra de Soledad Fariña (Antofagasta, Chile 1943): El Primer Libro (1985), Albricia (1988), En Amarillo Oscuro (1994) y Pac Pac Pec Pec (2012). En ellos la madre mítica se relaciona con lo desaparecido, reprimido u oculto, con rituales prehispánicos. Al mismo tiempo, se funde con la naturaleza del paisaje desértico y marítimo, y es, finalmente, palabra primigenia, voz y silencio que evidencia una subjetividad en resistencia a la cultura patriarcal ${ }^{2}$. Al respecto, Mistral en su célebre conferencia de Uruguay, titulada "Como escribo", afirma:

La poesía es en mí, sencillamente, un regazo, un sedimento de la infancia sumergida. Aunque resulte amarga y dura, la poesía que hago me lava de los polvos del mundo y hasta de no sé qué vileza esencial parecida a lo que llamamos pecado original, que llevo conmigo y que llevo con aflicción. Tal vez el pecado original no sea sino nuestra caída en la expresión racional y antirrítmica a la cual bajó el género humano y que más nos duele a las mujeres por el gozo que perdimos en la gracia de una lengua de intuición y de música que iba a ser la lengua del género humano. (554)

Viene al caso entender esta hermosa comparación como metáfora de la comunicación materna preedípica, a la que se refiere Julia Kristeva al estudiar lo imaginario y lo simbólico; especialmente, sus referencias a una semiótica preverbal y presimbólica, reprimida por el logos y el lenguaje (lo simbólico) (Kristeva, 1981), que parece coincidir plenamente con el planteamiento de Mistral recién citado. En efecto, Kristeva otorga especial significación a lo preedípico y lo maternal en la constitución de la subjetividad "femenil" (para usar un neologismo mistraliano), ya que el lugar del lenguaje poético -según la teórica- se relaciona con el retorno de lo reprimido, esto es, del "orden de lo preedípico". Sostiene

Cabe observar que Fariña es seguidora y estudiosa de Gabriela Mistral.

2 Sobre el tema de la madre mítica en la poesía de Soledad Fariña -en la misma línea desarrollada aquí- pueden verse los estudios publicados por Raquel Olea, Diana Bellesi, María Teresa Adriazola y Javier Bello. 
Kristeva que este retorno es más recurrente en la literatura femenina y en las "literaturas de vanguardia" (152 y ss.).

Por su parte, la poesía de Soledad Fariña ficcionaliza la palabra primigenia, tanto sus formas de escritura y sus imágenes (dibujos, fotos, iconogramas) como sus elementos de oralidad ${ }^{3}$.

\section{Nacimiento de la Escritura}

El Primer libro de Fariña inaugura un discurso que busca conectarse intertextualmente con las culturas originarias, concretamente con la cultura prehispánica maya-quiché, como una manera de reivindicación frente a la tradicional cultura colonizadora española, sobre todo en lo que significa revalorar las deidades telúricas. Ello se observa, por ejemplo, en el siguiente poema:

TODO TRANQUILO. INMÓVIL.

Había que pintar el primer libro pero cuál pintar

cuál primer tomar todos 1os ocres también

el amarillo oscuro de la tierra

capas unas sobre otras: arcilla terracota ocre

arañar un poco lamer 1os dedos para formar

esa pasta ligosa

untar 1os dedos los brazos ya estás abierto

páginas blancas abiertas no hay recorrido previo

tratar de hendir los dedos

Por qué tan tristes por qué así estos colores,

dicen, preguntan los choroyes de alas verdes

3 Entendemos el concepto de "ficcionalización" en el sentido en que lo plantea Mauricio Ostria (2001), para quien: "lo que canónicamente se entiende por literatura, es decir, la literatura escrita (valga la redundancia) en el proceso de construcción de mundos imaginarios, sólo puede producir efectos de oralidad, es decir, solo evocar manifestaciones orales con los medios de la escritura" (73). 
que pasan en bandadas

Por qué esa oscuridad, gritan...

todo tranquilo inmóvil apacible

(El primer libro 9).

La evidente intertextualidad de este fragmento con el Popol Vuh queda manifiesta con la siguiente cita del texto fuente: "Este libro es el primer libro, pintado antaño, pero su faz está oculta [...] He aquí el relato de cómo todo estaba en suspenso, todo tranquilo, todo inmóvil, todo apacible, todo silencioso, todo vacío, en el cielo, en la tierra..." (Anónimo A 3). Las imágenes de esta reescritura del Popol Vuh en el poemario de Fariña tienden a intensificar el aspecto sensorial (táctil, auditivo, visual e incluso, el gustativo a través del verbo "lamer"), en contraste con el texto sagrado maya-quiché. Este énfasis en lo sensorial se hace más intenso en imágenes femeninas y feminizadas intencionalmente mediante recursos como la personificación y la metonimia. Véase, por ejemplo, en Albricia, como las palabras, más allá de la sintaxis descoyuntada, obedecen al ritmo erótico del abdomen y al orgasmo en la vinculación metafórica 'naranjabulva' que la memoria abre como un libro-lengua hacia el pasado que es también esencia femenina:

\section{CRUJEN LOS HUESOS DE ESTA PRISIÓN}

Intento abrir al ritmo de mi abdomen

un hueco a la palabra Se encabritan las olas

de mi cabeza

Aúllo Aúlla

el celador pliegue

de mi memoria

(mi naranja guardada por cáscara porosa)

Nadie entra en esta esfera Apretada

me sumo Zumo líquidos que irrigan

mis conductos Pero las fosas husmean 
buscando la fragancia Mi naranja olorosa

apretada resiste pero el dedo se hunde

desgarrando Me abro en gajos amarillos

y crujo este sonido al desmembrarme

(10).

\section{En Amarillo Oscuro y su Reescritura en Pac Pac Pec Pec}

El poemario titulado En amarillo Oscuro persiste en la idea de rescatar formas o imágenes de una lengua originaria de las mujeres, al decir de Gabriela Mistral, a través de imágenes fuertemente relacionadas con una madre mítica, nortina y andina:

Colores nunca vistos

guarda la cuenca del ojo

sabores muy antiguos

debajo de la lengua

me dice separando los labios

La reescritura del mismo poema en $\mathrm{Pac} P a c P e c P e c$, aparece relacionada con el libro del cronista Felipe Guamán Poma de Ayala, El primer nueva corónica y buen gobierno (1600-1615). Ahora, el texto de Fariña imita un palimpsesto, es decir, un "Manuscrito antiguo que conserva huellas de una escritura anterior borrada artificialmente" (Dicccionario de la $R A E$ ). Lo que origina, como explica Gérard Genette (1989), una “duplicidad de objeto"; esto es:

...en el orden de las relaciones textuales, puede representarse mediante la vieja imagen del palimpsesto, en la que se ve, sobre el mismo pergamino, cómo un texto se superpone a otro al que no oculta del todo sino que lo deja ver por transparencia. Pastiche y parodia, se ha dicho justamente, "designan la literatura como palimpsesto": esto debe entenderse más generalmente de todo hipertexto... (495)

Esta última versión del Poemario de Fariña construye, efectivamente, una intertextualidad con el capítulo “Abociones" de la Crónica de Guamán 
Poma, término relacionado a los malos presagios. El texto de Fariña opera como "hipertexto" del texto cronístico ("hipotexto") (Génette, 1989). Así, el texto de Guamán Poma es impreso como trasfondo de los primeros poemas de Pac Pac Pec Pec. Por ejemplo, el siguiente fragmento de la célebre Crónica aparece íntegramente citado, acompañando un poema de Fariña:

Los dichos abocioneros, agüeros que sustener los yndios antigos de los Yngas y en este tienpo lo tienen desto de atitapyata pyauanmi [La mala fortuna me ha maldecido], acoyraqui [infortunio], tiyoyraqui [calamidad].

Quando le paresen o se les entran en sus casas las culebras y cantar de lechuzas y muchuelos, morciégalos que los llaman tuco, chucic, pacpac, pecpe, [...] El búho, la lechuza, el paqpaq, p'iqpi, chiqallu (especies de búhos) me han llamado. Una mariposa nocturna ha entrado dentro de mí. ${ }^{5}$ Los fuegos fatuos me han arrastrado el cadáver. ¿Quizá cuándo vamos a morir? ... (Guamán Poma de Ayala 255)

Dentro de los procedimientos de ficcionalización intertextual está, asimismo, el hecho de que el título del poemario Pac Pac Pec Pec evoca el nombre del búho o lechuza, intencionalmente feminizado en los poemas de Fariña. En este texto se relaciona con la simbología incaica asociada a dicha ave como mensajera de los misterios de la noche yde la muerte, y junto al carácter onomatopéyico de su nombre, el empleo de tal expresión constituye un intento de privilegiar lo prehispánico por sobre lo europeo, lo fónico sobre lo gráfico,con toda la relevancia que esta tentativa tiene en el proceso de la conquista de América. Un ejemplo de esto es el poema de En amarillo oscuro, reescrito en Pac Pac Pec Pec, donde se poetiza el tópico de la mariposa y donde la reciente cita de Guamán aparece otra vez, funcionando como hipotexto, detrás de este poema, que, por consiguiente, se constituye en una reescritura de la cita, como queda en evidencia:

4 Genette explica: “Se trata de lo que yo rebautizo de ahora en adelante hipertextualidad. Entiendo por ello toda relación que une un texto B (que llamaré hipertexto) a un texto anterior A (al que llamaré hipotexto en el que se injerta de una manera que no es la del comentario" (14).

5 El destacado es mío. 


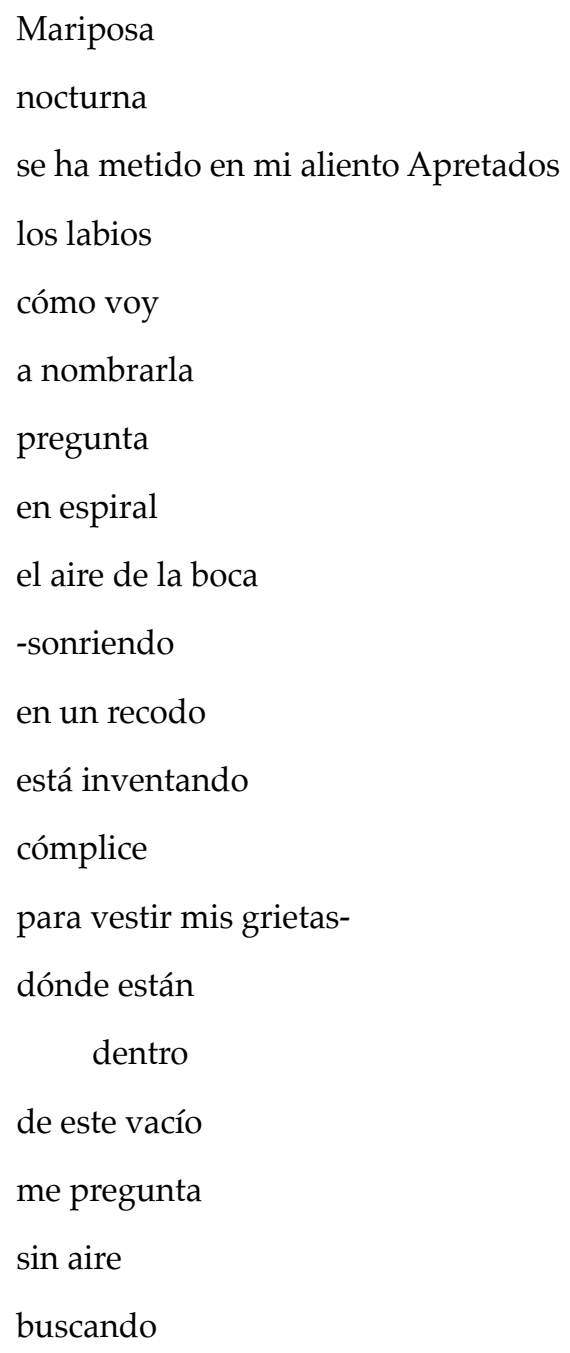

azules verdes $\quad$ (Pac Pac Pec Pec 9).

Las imágenes de la oralidad en este poema, como "el aire de la boca", "mi aliento", "nombrarla", fuera de aludir al nacimiento o renacimiento de una lengua de mujer, nombrando lo femenino, guardan relación con la tesis de Martin Lienhard (1990), según la cual no fue la imposición de un nuevo poder político lo que produjo un mayor impacto en los pueblos indígenas con la llegada de Colón, sino la "valoración extrema, sin antecedente ni en las sociedades autóctonas más 'letradas' de la notación 
gráfica o trascripción gráfica -alfabética del discurso, especialmente del discurso del poder" (27). El impacto de la letra sobre la oralidad transforma ciertamente la subjetividad de un pueblo para quien la palabra hablada era la vía de comunicación entre las personas y entre estas y la naturaleza. Aun cuando la letra ha tenido un dominio evidente, la oralidad, lejos de extinguirse, ha manifestado una fuerte resistencia.

Esta constante intertextualidad de los libros de Fariña con textos de la literatura prehispánica y colonial, puede tener relación, en el decir de Patricio Núñez, con el hecho de que: "Nuestra lucha contra el poder español, permitió desestimar muchos valores culturales de origen español, quedamos sin Identidad, pero al mismo tiempo, contradictoria y románticamente, se valoraron nuestras raíces indígenas" (Núñez 29) ${ }^{6}$.

Coincidiendo con esta misma idea, al final de Pac Pac Pec Pec, Soledad Fariña incluye un fragmento de Dioses y hombres de Huarochirí. ${ }^{7}$ Asimismo, como mecanismo que figura un palimpsesto, se citan a modo de trasfondo del mismo poemario, poemas de En Amarillo oscuro, fragmentos de un estudio sobre la cultura andina: Culto del agua en el antiguo Perú de Rebeca Carrión (1955), específicamente, los comentarios de lugares al Sur de Los Andes sobre costumbres indígenas prehispánicas.

No todos los fragmentos citados en $\mathrm{Pac} \mathrm{Pac} \mathrm{Pec} \mathrm{Pec}$ se atienen estrictamente a la fuente original. Así, el texto titulado "Yo, Choque Suso", basado en Dioses y hombres de Huarochirí, cambia a primera persona gramatical el original escrito en tercera persona. Para visualizar el procedimiento, citamos con numeración, primero, el texto original y, luego, el incluido en Pac Pac Pec Pec:

1. Ella se llamaba Chuquisuso. Un día regaba, llorando, su campo de maíz; lloraba porque la poquísima agua no alcanzaba para mojar la tierra. Entonces Pariacaca bajó [...] y le preguntó "Hermana, ¿por qué sufres?" Ella le contestó "mi campo de

6 El imperio Inkaico, afianza la dominación de la gran nación andina sobre otros pueblos andinos desde el sur de Colombia hasta el centro de Chile [...] Las diferentes organizaciones sociales conquistadas, sufrieron transformaciones, pero conservaron en gran medida, sus identidades culturales, siempre que no estuvieran en contradicciones con los intereses económicos del imperio. Es por eso, que los atacameños conservan su lengua, parte de sus costumbres y tradiciones andinas (locales y regionales), en esta integración forzada, pero dentro de la unidad cultural andina (Núñez 70-1).

7 Traducción de José María Arguedas del manuscrito anónimo, sagrado de los Andes peruanos, recopilado por el sacerdote cuzqueño Francisco de Ávila a fines del siglo XVI. 
maíz muere de sed. "No sufras -le dijo Pariacaca $\urcorner-$ Yo haré que venga mucha agua de la laguna que tienen ustedes en la altura Pero acepta dormir antes conmigo".

"Haz venir el agua primero, cuando mi campo de maíz esté regado, dormiré contigo", le contestó ella. "Está bien" aceptó Pariacaca; e hizo que viniera mucha agua... Y cuando iba avanzando el trabajo, por encima de San Lorenzo, en un cerro de repente se echó a volar una perdiz. Saltó "pic, pisc" gritando." El zorro quedó aturdido; "¡Huac!", diciendo, se cayó; rodó hacia abajo... (Anónimo B 46-47).

\section{YO, CHOQUE SUSO}

le respondí al Dios Pariacaca,

que trajese el agua primero

con la abundancia que prometía,

que yo acudiría de buena voluntad

y Él me tendría a gusto...

Él,

subiendo a la represa hizo venir tanta agua

que bastó para regar mis secas chacras

y yo quedar contenta,

así me pidió Pariacaca que yo cumpliese

la promesa, le contesté que hartos días quedaban

y tiempo había en que se pudiese hacer...

así, haciendo su oficio

y llegando a aquel lugar con su cordel

vino de lo alto una perdiz volando

y para decirlo como los indios lo cuentan 
venía haciendo un ruidito que decía PichPich, y el descuidado raposo diciendo Huac, turbado rodó cerro abajo (Pac Pac Pec Pec 77-80).

Es muy significativo que, aunque el último texto reproducido tenga un Dios patriarcal, está centrado en el punto de vista del personaje femenino, instaurado como madre mítica por los pueblos originarios referidos. Como ya apuntamos, además, el mecanismo del palimpsesto integra fragmentos de Culto del agua en el antiguo Perú, de Rebeca Carrión, que fortalece la idea de Fariña de enraizar su escritura en una tradición prehispánica y andina. Algunos textos de Carrión, como el siguiente, aparecen citados a manera de trasfondo a los poemas de $\mathrm{Pac}$ Pac Pec Pec:

La fecunda imaginación del artista milenario, perennizó en la piedra aún las romerías a estos lugares sagrados, los sacrificios de llamas que se realizaban, las ofrendas de chicha que se llevaban. Todo ello puede apreciarse en ciertos monumentos extraordinarios del arte indio, como en las fuentes simbólicas denominadas "Las moyitas" y Lavapatas en San Agustín, Colombia, y en los monolitos de carácter ecológico de Saywite, en Abancay, Perú. (27).

Otra vez, entonces, se está aludiendo a figuraciones de madres míticas precolombinas. Es muy significativo, asimismo, que entre los lugares mencionados de pinturas y tallados de animales en piedra estén las serranías entre Taltal y Antofagasta, donde "los indígenas se expresaron con técnica de pintura llana en tintes exclusivamente rojos", según el fragmento citado de Carrión en Pac Pac Pec Pec (49). No puede ser casual la mención de Antofagasta, lugar donde nació Soledad Fariña, lo que, más allá del contexto extraliterario, de alguna forma ficcionaliza el lugar de nacimiento también como madre mítica. Es más, la poeta incluye un poema referido a estas pinturas, superpuesto a la cita de Carrión:

(veo hombres guiando

caravanas de llamas 
veo hileras de músicos

parejas de bailarines

veo lagartos peces

pintura en

tintes rojos)

(Pac Pac Pec Pec 47).

\section{Mujeres, Madres y Diosas Andinas}

Los fragmentos del estudio de Carrión, citados en Pac Pac Pec Pec, aluden también a las deidades femeninas, constituyéndose así en otro recurso para hacer presente la figura de la madre mítica, nortina-andina:

En estas tradiciones, especie de códices, están contenidas muchas de las concepciones que interesan al tema. Figura una diosa femenina, la luna, que simboliza las lluvias, el agua que fertiliza la tierra, en doble modalidad, como deidad celeste, en el cielo con un cántaro de agua o paccha perforada con la que vierte las lluvias; o como deidad terrestre, personificada en una linda doncella, que personifica la tierra, dedicada al cultivo del maíz, papa o quinua, y que tiene como atributo o emblema, un cántaro de chicha que se convierte en un manantial del que mana abundante agua para la irrigación de las tierra... (20)

A propósito de lo anterior -la representación de lo femenino en los poemas de Fariña-, es bueno recordar la reflexión de la teórica feminista Patrizia Violi, quien en su artículo "Sujeto lingüístico y sujeto femenino" (1990), afirma: "es hasta demasiado evidente que la corporeidad, la siquis y lo sensible, sean referencias inmediatas e imprescindibles para toda reflexión sobre lo femenino" (136). Ejemplo extraordinariamente vivo es la representación de la sujeto hablante de Albricia, fundida con la naturaleza nortina y sintiéndola hasta en sus sabores de lengua, como vivencia corporal de un habla primigenia: 


\section{VIAJO EN MI LENGUA}

de arena pantanosa

dos vocales $\quad \mathrm{O} \quad \mathrm{E}$

Viajo y rozan los bordes mi arenilla dormida

Adentro más adentro de la cavidad sonora

tus vocales las mías

en el ronco gemido

Me aferro a mis moluscos Penetro las papilas

Adentro más adentro llego hasta el estertor

al eco de otra lengua La camino

recorro la nostalgia la cerco

Pero a la piel no llegan claros los envíos

Qué sintaxis Qué paisajes que mis ojos no vieron

Quieren brotar desde esas aguas

$$
\text { y tu lengua mi lengua (Albricia9). }
$$

La identificación, tanto de la sujeto hablante como de la madre mítica, con la naturaleza y la cultura, nortinas y andinas, es una constante en todos los poemarios. Así, en En amarillo oscuro:

La luz oblicua me horada

Azules y grises superpuestos me conforman

Estoy plena de quietud Pero hablan

mis bordes en amarillo oscuro

tengo un pequeño caracol petrificado en mi base

pero es mi luz la que habla

(29). 
Dos profundas fallas

Me hienden los costados

Carcomida en abrupta ladera

Me inclino recreando

Siete terrazas verdes

(39).

Estos mismos poemas son reeditados en $\mathrm{Pac} \mathrm{Pac} \mathrm{Pec} \mathrm{Pec} \mathrm{con} \mathrm{trasfondo}$ de imágenes de Macchu Picchu, lo que desborda las significaciones relacionadas con la cultura andina, introduciendo otras formas de intertextualidad, esta vez, icónico-lingüísticas.

A la luz de los planteamientos de Lacan (1971) -el significante tiene preeminencia sobre el significado, el cual se desliza permanentemente bajo él, más precisamente, bajo la barra que resiste a la significación, concluimos que el significado se articula en profundidad, como sobre los diferentes pentagramas de una partitura. Un cierto orden "polifónico" es lo que permitiría a la palabra "significar algo totalmente diferente de lo que ella dice", hacer "oír otra cosa", "entre líneas" (Lacan 189). Este entender que cada palabra dice lo que dice y además otra cosa se logra, entre otros recursos, con la peculiar presentación gráfica de los poemas de Fariña, disposición que permite múltiples lecturas simultáneas. Presentamos, a modo de ejemplo, algunos versos que representan una relación, incluso lésbica, entre sujeto hablante y madre mítica:

Amarillas

fisuras atraen

Nuestros dedos

Escarbamos

los rostros reconocen

la Imagen

YO TÚ

(Albricia 22). 
Sobre el título, Albricia, Roberto Merino (1989) comenta:

El título del libro cubre tres significaciones importantes: por un lado es la contradicción de alba, y por otro se suma a una serie de palabras (ijar, valva, drupa, etcétera) que designan cavidades protagónicas en procesos de fusión o fecundación. Técnicamente, albricia es una suerte de agujero que se practica en los moldes donde se funden metales para acelerar al aireo del proceso.

Es sabido que, para remediar su mal, la mujeres estériles de Pafos (antigua ciudad chipriota célebre por templo de Venus, según la enciclopedia) suelen cruzar ceremonialmente a través de piedras horadadas. El simbolismo habitual de los agujeros se vincula en la tradición poética a los ritos de fertilidad. Ahí está aparentemente una clave que permite suponer en el libro de Soledad Fariña la existencia de un proyecto de poesía femenina: el descubrimiento, la invención, la investigación de un modo de hablar del cuerpo y sus incidencias que sea estructuralmente un modo de hablar de un rasgo femenino diferencial: la fecundidad... (35)

Esta identificación de la sujeto hablante con objetos sagrados, contextualizados en culturas prehispánicas, es desarrollada en la poesía de Fariña como figura, en el siguiente poema sobre un altar ritual, la hornacina:

Me han cavado hornacinas

para honrarme

unas al lado de otras

nos decimos palabras misteriosas:

arena pálida fósil

caracol humeante

(Fariña, Pac Pac Pec Pec 32).

Este poema proveniente de En amarillo oscuro aparece reeditado con una imagen de Macchu Picchu como trasfondo en Pac Pac Pec Pec, reiterando así su referente sobre las culturas andinas prehispánicas.

La identificación de la hablante de los poemarios con lo sagrado primitivo o primigenio universal en ocasiones, como la imagen 
anteriormente citada; pero mayoritariamente asociado a lo prehispánico, la relaciona con una utopía, la de refundar sentidos nuevos del mundo, como respuesta significativa a la historia actual, y especialmente la de los tiempos de la Dictadura en Chile en cuyo contexto fueron publicados al menos los dos primeros poemarios y sobre lo cual hay un pronunciamiento de la autora en una entrevista:

...volviendo al año 85, el mismo año que se publica El primer Libro, sucede el evento tal vez más horrible de todos los años de represión. Por lo menos el más público, el secuestro y degollamiento de un profesor y un apoderado del colegio donde estudiaban mis hijos. La crudeza de ese acto nos hizo dudar incluso de lo que llamamos "sentido común". Cuando nos reunimos los apoderados en el colegio la noche del secuestro, todos decíamos que por sentido común no les podían hacer nada, ya que había sido a pleno día en una calle del barrio alto. Era viernes. Imagínate el sábado cuando aparecen, qué les podías decir a tus hijos, dos personas tan cercanas que no han muerto en un accidente, ni en una guerra, ni en una escaramuza, ni siquiera han sido fusilados, sino ¡degollados! Escarmiento no sólo para "quienes andábamos metidos en problemas", sino también para los niños, en un colegio.

Cómo relatas algo así, cómo escribes algo así. Ese es el contexto, el ambiente vivido, la realidad. Cómo inventar un lenguaje que dé cuenta a la vez de tus pulsiones internas, de tu relación histórico-literaria con la palabra y que a la vez "escriba" ese sin sentido que te está tocando vivir... ("El Primer Libro. Soledad Fariña", párr. 17-18).

\section{A Modo de Conclusión}

Las figuraciones de la cultura andina en los poemarios analizados evocan la complejidad resultante del conflictivo encuentro de las formaciones discursivas de conjuntos sociales ágrafos junto a los letrados, dando por resultado múltiples formas de interrelación difíciles de aprehender desde una concepción letrada. Al respecto, Cornejo Polar (1994), señala: “La construcción de estos discursos delata su ubicación en mundos opuestos, la existencia de zonas de alianzas, contactos y contaminaciones" (17); así, los textos deben ser leídos "como espacios 
lingüísticos en los que se complementan, solapan, intersectan o contienden discursos de muy variada procedencia [...] de filiación sociocultural disímil" (Ibid.). ${ }^{8}$

Por otra parte, como señala Beatriz Pastor (1996), en América Latina la neutralización simbólica de los horrores de la subyugación, la opresión, la explotación y la marginalidad, origina una dinámica de resolución de contradicciones que impulsa el pensamiento y la escritura, y a veces sus referentes de acción, hacia la neutralización de impases históricos, sociales y culturales. La autora pone con acierto el énfasis en las figuraciones del sujeto, en su voluntad, deseo y motivaciones que lo llevarían al encuentro de la armonía (Pastor 36-42). Para los poemas aquí analizados, esta armonía se concreta en el encuentro de la hablante con su madre mítica, tal como la hemos caracterizado, para dar origen a una ficticia lengua originaria femenina en la escritura de Fariña, que también se caracteriza por la heterogeneidad discursiva recién referida.

Los contenidos de este pensamiento utópico "se manifiestan esencialmente en representaciones de la fantasía y constituyen el modo con que "el sujeto se reserva la libertad de una reacción sobre lo que no debiera ser" (Bloch 137). Así, la utopía va "de la mano" con "la fantasía artística" (206), pues su fuente está en los "sueños soñados despierto" (Ibid) y nace de la insatisfacción de las condiciones actuales de vida de los sujetos. En los poemarios analizados, tal vez este deseo-sueño sea la necesidad de darle sentidos utópicos y ficticios al lugar de nacimiento de su autora y a su país, Chile.

8 Mauricio Ostria (2011), ampliando el concepto de Cornejo Polar, afirma que es heterogéneo: ...un discurso en el que se incorporan estructuras narrativas, descriptivas, argumentativas, explicativas y/o poéticas es un discurso heterogéneo; también lo es, si ese discurso contiene expresiones pertenecientes a lenguas, sociolectos, sincronías o estilos diversos, si en su interior se relacionan mediante oposiciones, contrastes, disyunciones o conjunciones elementos propios de dos o más universos de discurso, lenguas y metalenguas, discurso funcional y discurso repetido o fosilizado; si se mezclan expresiones orales o escritas o se combinan elementos verbales, paraverbales y no verbales. Y que todo esto suceda es lo más frecuente en el tráfico comunicativo. (307) 


\section{Referencias Bibliográficas}

\section{De la autora}

Fariña, Soledad. El Primer Libro. Santiago de Chile: Amaranto, 1985. . En Amarillo Oscuro. Santiago de Chile: Surada, 1994. . Albricia. [1988]. $2^{\mathrm{a}}$ Ed. Santiago de Chile: Cuneta, 2010. . Pac Pac Pec Pec. México D. F.: Proyecto Literal, Literatura y Alternativa en Servicios Editoriales, Colección Pico de Gallo, 2012.

. "El Primer libro. Soledad Fariña". Revista LDD. Entrevistas Mi primera vez por Ángela Barraza, s.f.12 Jun. 2011<http://www.ldds.tk>

II. Teórica y Crítica

Anónimo A. El libro del Consejo (Popol Vuh). [1939]. Trad. y notas Georges Raynaud, J.M. González, Miguel Ángel Asturias. Prólogo Francisco Monteverde. Introducción Maricela Ayala. $5^{\text {a }}$ Ed. $2^{\text {a }}$ Reimp. México: UNAM, 2004.

Anónimo B. Dioses y hombres de Huarochirí. Traducción y Prólogo por José María Arguedas. Apéndice por Pierre Duviols. [1966]. $2^{\text {a }}$ Ed. México DF: Siglo XXI Editores, 1975.

Bloch, Ernst. El principio Esperanza, tomo I. [1959]. Traducción del alemán por F. González Vicen. Madrid: Aguilar, 1977.

Carrión, Rebeca. El culto al agua en el antiguo Perú. [1955]. 2a Ed. Lima: Instituto Nacional de Cultura del Perú, 2005.

Cornejo Polar, Antonio. Escribir en el Aire: Ensayo sobre la heterogeneidad cultural en las literaturas andinas. Lima: Horizonte, 1994.

Genette, Gérard. Palimpsestos. La literatura en segundo grado. [1962]. Trad. del francés Celia Fernández Prieto. Madrid: Taurus, 1989. 
Guamán Poma de Ayala, Felipe. El primer nueva corónica y buen gobierno.

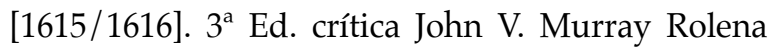
Adorno. Trad. y análisis textual del quechua Jorge L. Urioste. México DF, 1992.

Kristeva, Julia. Semiótica 1. [1969]. Trad. del francés José Martín Arancibia. $2^{a}$ Ed. Madrid: Fundamentos, 1981.

Lacan, Jacques. Lectura estructuralista de Freud. México: Siglo XXI, 1971. Laplanche, J. y J. B. Pontalis. Vocabulaire de la Psychanalyse. [1967]. 5a. Ed. Revisada. Paris: Presses Universitaires de France, 1976.

Lienhard, Martin. La voz y su huella. Escritura y conflicto social en América Latina. [1990]. Lima: Horizonte, 1998.

Merino, Roberto. "Albricia de Soledad Fariña. El viaje de la lengua por los cuerpos". Revista APSI 295 (13 de marzo de 1989): 35 .

Mistral, Gabriela. "Cómo escribo". [1938]. Antología Mayor. Prosa. Tomo II. Santiago, Chile: Cochranne S. A., 1992. 553-554.

Núñez, Patricio. Nuestras Identidades: Reflexiones. A propósito de la prehistoria de Tarapacá y Antofagasta. Antofagasta, Chile: Universidad de Antofagasta, Dirección de Extensión y Comunicaciones, Instituto de Investigaciones Antropológicas, 2001.

Ostria, Mauricio. "Literatura oral, oralidad ficticia", Estudios Filológicos 36 (2001): 71-80.

- "Algunas notas sobre heterogeneidad discursiva en textos poéticos chilenos". Williams y L. Bernucci Eds. Literatura a ciencia cierta: Homenaje a Cedomil Goic (2011) Newark: Juan de la Cuesta. 307-326.

Pastor, Beatriz. El jardin y el peregrino. Ensayos sobre el pensamiento utópico latinoamericano 1492-1965. Amsterdam, Atlanta: Editions Rodopi, 1996.

Real Academia Española. Diccionario de la Lengua Española. 2 Vols. $21^{\text {a }}$ Ed. Madrid: Espasa Calpe S. A, 1992. 
Rosolato, Guy. Essais sur le Symbolique. París: Gallimard, 1969.

Violi, Patrizia. "Sujeto lingüístico y sujeto femenino". Giulia Colaizzi (Ed). Feminismo y Teoría del Discurso. Madrid: Cátedra, 1990. 127-140. 


\section{ANEXO:}

Ilustraciones de Pac Pac Pec Pec

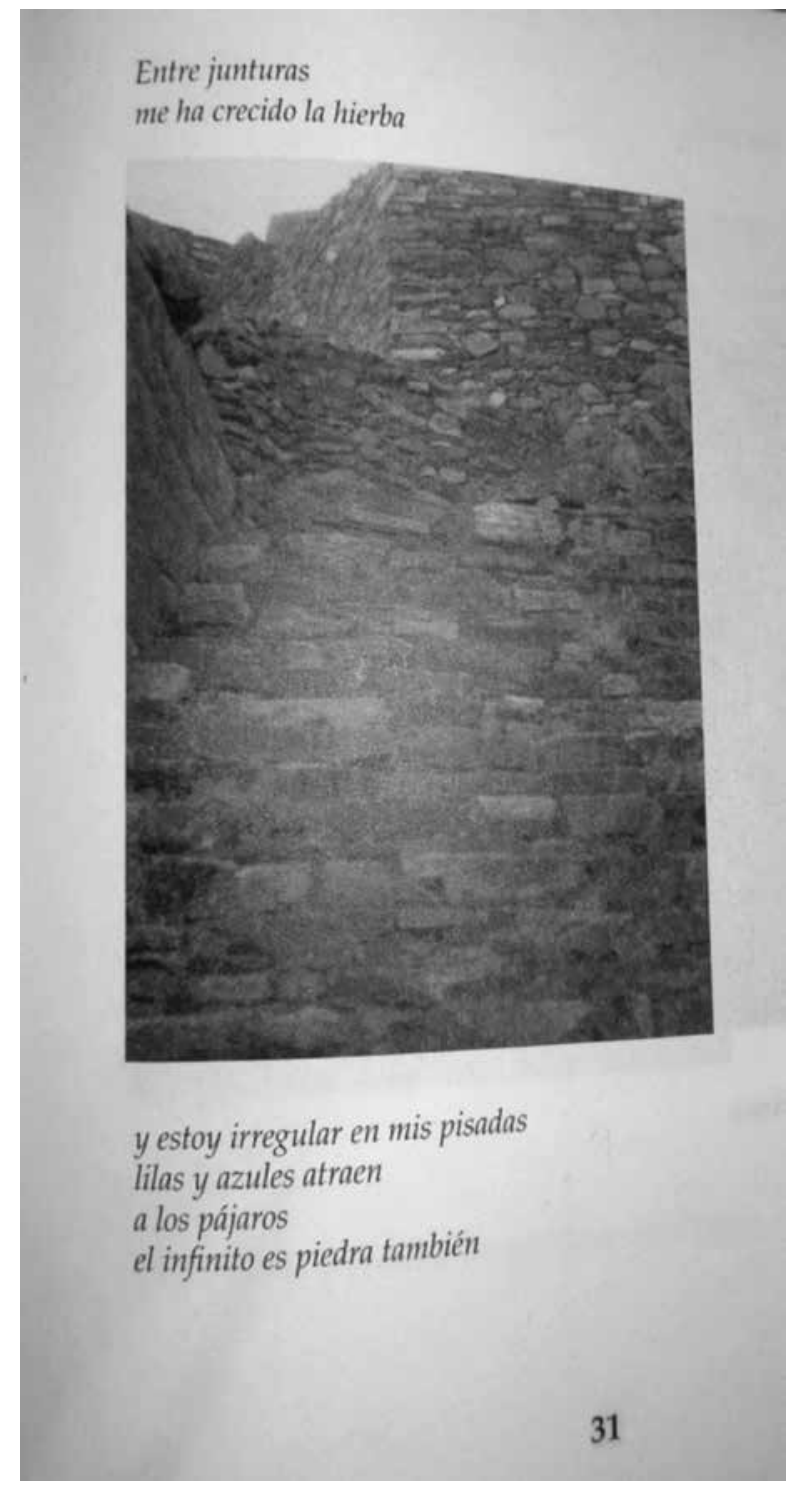



Los dichos abocioneros, agiieros que sustener
los indios antigos Marimen $y$ en este tiemdesto de atitap[La mala fortuna decido, acoyraqui tiyoyraqui [calamile paresen o se les casas las culebras chuzas y muchuelos que los llaman pacpac, pecpe, chicuuan. TaparanUro nina ayacta aychapas maycan uazupayta ayzan uarMariposa nocturna se ha metido po lo tienen en mi aliento Apretados ya tapy/aummi los labios cómo voy a nombrarla pregunta en espiral el aire de la boca entran en sus -sonriendo en un recodo está inventando los, morciégacomplice tuco, chiscic, para vestir mis grietas-
donde están dentro de este vacio me pregunta me ha mal[infortunio], dad]. Quando y cantar de lecarita. [E] búho, sin aire Mosoll. Atocin buscando azules verdes co yaycuuan. zaycuuan. $Y$ mitam ychapas la lechuza, e pagpaq, p'iq pi, chiqgallu búhos me han llamado, Una mariposa nocturna ha entrado dentro de mí. Los fuegos fatuos me han àrrastrado el cadáver. ¿Quizá cuándo vamos a morir? 